\title{
Evaluation of frequency and intensity of asymptomatic anisocytosis in the Japanese dog breeds Shiba, Akita, and Hokkaido
}

\author{
Olga Aniołek ${ }^{1,2}$, Agnieszka Barc ${ }^{3}$, Anna Jarosińska ${ }^{3}, Z_{\text {dzisław Gajewski }}{ }^{1,2}$ \\ Warsaw University of Life Sciences - SGGW, Faculty of Veterinary Medicine, \\ ${ }^{1}$ Department of Large Animal Diseases, ${ }^{2}$ Veterinary Research Centre, \\ ${ }^{3}$ Scientific Circle of Veterinary Students, \\ Warsaw, Poland \\ Received May 4, 2017 \\ Accepted December 19, 2017
}

\begin{abstract}
Microcytosis is observed in healthy Japanese breed dogs. The aim of the study was to evaluate the frequency and intensity of asymptomatic anisocytosis using a three-grade scale in Japanese dog breeds with special emphasis on the following indices: mean cell volume, mean cell haemoglobin, mean cell haemoglobin concentration, and red blood cell distribution width. The retrospective study included analyses of blood morphology and blood smear for clinically healthy Japanese dog breeds Shiba, Akita, and Hokkaido aged from 6 months to 14 years, performed as a part of preventative care. A total of 74 dogs of both sexes were qualified for the study. The group included both neutered and non-neutered animals (Akita - 17 females, 12 males, Shiba - 24 females, 18 males, Hokkaido - 2 females, 1 male). The blood smear revealed significant anisocytosis in $60.8 \%$ and mild anisocytosis in $28.4 \%$ of the tested dogs $-89.2 \%$ in total. Microcytosis was reported for $25.7 \%$ of the tested Japanese breed dogs. Reduced mean cell haemoglobin and mean cell haemoglobin concentration were diagnosed in $75.7 \%$ and $40.5 \%$ of dogs, respectively. Red blood cell distribution width as an anisocytosis indicator exceeded the norm in $12 \%$ of the tested dogs. Compared to mixed breed dogs, the Japanese breeds had a reduced mean cell volume, mean cell haemoglobin concentration and significant anisocytosis in the blood smear as well as a higher red blood cell distribution width indicator. Veterinarians should consider these differences when interpreting the results of morphological blood tests.
\end{abstract}

MCH, MCHC, red blood cell distribution width

Red cell distribution width (RDW) as an anisocytosis indicator is a quantitative measure of the range of variation of the circulating red blood cells (Neiger et al. 2002; Hodges and Christopher 2011; Montagnana et al. 2012; Mazzotta et al. 2016). It is a routinely measured indicator by haematology analysers (Lippi and Plebani 2014). This indicator is usually elevated when insufficient total red blood cell count (RBC) production is observed as a result of e.g. vitamin B12 or iron deficiency, exacerbated red cell destruction, haemolysis, after a blood transfusion or in severe inflammatory states. Changes in this indicator are observed in the course of numerous systemic conditions such as renal diseases or nutrition shortages (Hellhammer et al. 2016). Increased RDW is also observed in cases of RBC deformability (Patel et al. 2013). It is also treated as an indicator for evaluation of red blood cell functionality (Patel et al. 2013; Lippi et al. 2014). Red cell distribution width is a valuable prognostic lethality marker for humans in the course of heart diseases (Campora et al. 1987; Felker et al. 2007; Aung et al. 2013). Changes in the haematology for different dog breeds have been documented. Separate referential values were established for Greyhounds, which have higher haematocrit (HCT), mean cell volume (MCV) and haemoglobin (HGB) concentration and a lower total platelet count (PLT) and total white blood cell (WBC) count compared to other breeds (Porter and Canaday 1971; Sullivan et al. 1994; Guyton and Hall 2006; Campora et al. 2011; Zaldivar-Lopez et al. 2011). Physiological macrocytosis was diagnosed in miniature breeds and standard 
poodles (Schalm 1976). Compared to mixed breed dogs, Dachshunds have a higher mean platelet volume (MCV), HCT, RBC and a higher HGB concentration (Torres et al. 2014). Idiopathic thrombocytopaenia connected to beta-tubulin mutation in Cavalier King Charles Spaniels (Singh and Lamb 2005; Davis et al. 2008) or microcytosis in Asian dog breeds reported in literature (Tanabe 2006; Battison 2007) can serve as another example. Increased popularity of breeds such as Shiba or Akita has been recently observed in Poland, sparking the need to analyse asymptomatic microcytosis in more detail. The aim of the study was to evaluate the frequency and intensity of asymptomatic anisocytosis using a three-grade scale in Japanese dog breeds with special emphasis on the indices of $\mathrm{MCV}$, mean cell haemoglobin $(\mathrm{MCH})$, mean cell haemoglobin concentration (MCHC), and RDW.

\section{Materials and Methods}

\section{Sample collection}

Blood samples were taken from clinically healthy dogs aged 6 months to 14 years (median 2.5 years; Akita median 2 years; Shiba - median 4 years; Hokkaido - median 5 years) as a part of animal preventative care. The study was conducted at the Department of Animal Diseases with Clinic of Warsaw University of Life Sciences, in the years 2016-2017. The majority of dogs were born on breeding farms and had appropriate documents certifying their breed. The dogs came from both Polish and foreign breeders. A total of 74 dogs of both sexes, neutered and non-neutered, were qualified for the study (Akita - 17 females, 12 males, Shiba - 24 females, 18 males, Hokkaido - 2 females, 1 male). Their health condition was confirmed by a veterinarian based on an overall clinical examination following an interview with special emphasis on the history of diseases and undergone treatments. The blood samples for haematological analysis were collected into tubes with ethylenediamine tetraacetic acid (EDTA) anticoagulant from the cephalic vein. The storage time for the samples before analysis did not exceed $4 \mathrm{~h}$.

\section{Haematological analysis}

Quantitative examination of the peripheral blood was performed using a veterinary haematology analyser (Mindray, BC- 2800 Vet). The following indices were evaluated: total white blood cell count (WBC), lymphocytes (LIMF), monocytes (MON), granulocytes (GRAN), total red blood cell count (RBC), haemoglobin (HGB), haematocrit (HCT), mean cell volume (MCV), mean cell haemoglobin (MCH), mean cell haemoglobin concentration (MCHC), red cell distribution width (RDW), total platelet count (PLT), mean platelet volume (MPV), platelet distribution width (PDW), platelet haematocrit (PCT).

Qualitative study was performed after staining the samples using Hemacolor ${ }^{\circledR}$ (HEMAVET, Kolchem Polska). Stained blood smears were evaluated under a light microscope equipped with a camera (Olympus, BX 43) and photographic documentation was created (Olympus, cellSens Standard). The first stage of the qualitative evaluation involved estimating the number of leukocytes with regard to the populations as well as estimating the platelet count and platelet morphology. Subsequently, attention was focused on the qualitative evaluation of the erythrocytic system. The erythrocyte morphology evaluation involved evaluation of the erythrocyte size, shape, colouring and presence of possible cell inclusions. Thereafter, the microcytes visible in the standard field of view at $\times 100$ magnification were counted. The following assumptions were made: up to 3 microcytes in the standard field of view - no anisocytosis, up to 7 - mild anisocytosis, more than 7 - significant anisocytosis. Qualification of the red blood cell as microcytes was performed on the basis of comparison of the erythrocyte's diameter to the mean erythrocyte diameter - normocyte - in the observer's standard field of view.

\section{Statistical analysis}

The statistical analysis was performed using statistical software. The $\mathrm{MCH}$ indicator was characterised by normal distribution. Kruskal-Wallis nonparametric test was applied for indices characterised by non-normal distribution, that is: $\mathrm{MCH}, \mathrm{MCHC}, \mathrm{RDW}$ and anisocytosis. The analysis of the selected indices of the erythrocytic system (MCH, MCHC, RDW, anisocytosis) was performed in total for all the qualified samples as well as with regard to the breed, sex and age within the given breed.

\section{Results}

Qualitative evaluation of blood smears revealed significant anisocytosis in $60.8 \%$ and mild anisocytosis in $28.4 \%$ of the tested dogs. Mild and significant anisocytosis was diagnosed in $33.3 \%$ and $50 \%$ of Shiba males, respectively. In females, this percentage was equal to $33.3 \%$ and $50 \%$. Mild anisocytosis was diagnosed in $33.3 \%$ of Akita males and 
in $17.64 \%$ of females. Significant anisocytosis was observed in $76.47 \%$ of Akita females. Microcytosis diagnosed on the basis of the MCV indicator evaluation was present in $25.7 \%$ of the cases (referential range 62-72 fl, minimum: $55.7 \mathrm{fl}$, maximum: $79.9 \mathrm{fl}$, median: 64.3 fl, standard deviation: 5.117), whereas anisocytosis indicator RDW exceeded the norm for $12 \%$ of the dogs (referential range: $11-15.5 \%$, minimum: $11.7 \%$, maximum: $17.1 \%$, median: $14 \%$, standard deviation: 1.135 ). A reduced MCV value for the Shiba breed was confirmed in $22.2 \%$ of males and $20.8 \%$ of females; for the Akita breed in $29.4 \%$ of females and $25 \%$ of males. For the Hokkaido breed, the values were reduced for $66 \%$ of females. Anisocytosis identified using the RDW indicator was confirmed for $11.6 \%$ of males and $16.6 \%$ of females of the Shiba breed and for $5.88 \%$ of females and $8.3 \%$ males of the Akita breed.

Reduced $\mathrm{MCH}$ and $\mathrm{MCHC}$ values were noted for $75.7 \%$ and $40.5 \%$ dogs, respectively (MCH referential range: $20-25 \mathrm{pg}$, minimum: $17.3 \mathrm{pg}$, maximum: $22.4 \mathrm{pg}$, median: 19.1 pg, standard deviation: 1.092; MCHC referential range: 300-380 g/l, minimum: $232 \mathrm{~g} / \mathrm{l}$, maximum: $340 \mathrm{~g} / \mathrm{l}$, median: $301 \mathrm{~g} / \mathrm{l}$, standard deviation: 20.255). Mean cell haemoglobin was noted for $44.4 \%$ Shiba males and $79.1 \%$ Shiba females; $82.5 \%$ females and $100 \%$ males of the Akita breed; and 100\% Hokkaido females. Reduced MCHC was diagnosed in 33\% Shiba males and $61.1 \%$ Shiba females, $47 \%$ Akita breed females and 33\% Akita males, and 33\% Hokkaido females. Dogs under the age of 1 year showed no statistically significant differences in the values of the erythrocytic system. All results are listed in the Table 1.

\section{Discussion}

The Japanese dog breeds Akita, Shiba and Hokkaido belong to the ancient Spitz type, relatively untouched by human breeding. In this study, the blood samples were taken from clinically healthy dogs aged from 6 months to 14 years. Even though the age distribution in the tested animals was wide, a recent study did not demonstrate a significant RDW difference between puppies and adult dogs (Rortveit et al. 2015). However, no data on RDW changes in old dogs are available. A MCVbased microcytosis was detected in $25.7 \%$ of the tested animals, which constitutes a significant percentage of the Japanese dog breed population. The results of the test including various dog breeds, indicated that the percentage of dogs with microcytosis is equal to $8.5 \%(86 / 1012)$. In cases where other indices of the erythrocytic system were also reduced, indicating anaemia, the percentage was equal to $47.8 \%$ of 86 cases (Peruzzi et al. 2010). Possible causes of microcytosis in dogs may be chronic iron deficiency, portacaval shunt, anaemia caused by inflammatory processes, prolonged treatment using recombined erythropoietin, copper deficiency, medicinal preparations or components inhibiting hem synthesis, myeloproliferative disorders with iron metabolism impairment, pyridoxine deficiency, and hereditary elliptocytosis in dogs. The test group for this study consisted of clinically healthy dogs, whose condition was assessed on the basis of an interview and a clinical test. The RDW was correlated negatively with haematocrit and haemoglobin concentration. No correlation between RDW and MCV was noted by Mazzotta et al. (2016), in contrast to the previous studies by other authors (Fig. 2), both in humans and dogs (Hampole et al. 2009; Guglielmini et al. 2013; Swann et al. 2014). Reasons for this divergence remain unclear. The presented study methods have their limitations. The obtained data (apart form $\mathrm{MCV}$ ) are not characterised by normal distribution, therefore in order to identify separate referential values, it is necessary to test a larger group of Japanese breed dogs. Vitamin B12 concentration as well as serum iron concentration levels were not evaluated. It is known that the red blood cell count and HGB concentration were lower 
Table. 1 Haematologic indices of the Akita, Shiba, and Hokkaido breeds.

\begin{tabular}{|c|c|c|c|c|c|c|}
\hline Indicator & Breed & $\mathrm{N}$ & Mean $\pm \mathrm{SD}$ & Min & Max & Range \\
\hline \multirow[t]{3}{*}{ WBC $\left(10^{9} / 1\right)$} & Akita & 29 & $12.4( \pm 5.9)$ & 5.5 & 28.2 & $6.0-17.0$ \\
\hline & Shiba & 42 & $11.6( \pm 3.2)$ & 5.8 & 21.2 & \\
\hline & Hokkaido & 3 & $11.8( \pm 4.6)$ & 6.5 & 15 & \\
\hline \multirow[t]{3}{*}{ LYMPH $\left(10^{9} / 1\right)$} & Akita & 29 & $3.6( \pm 2.4)$ & 1 & 11.5 & $0.8-5.1$ \\
\hline & Shiba & 42 & $2.7( \pm 1.3)$ & 0.9 & 7.7 & \\
\hline & Hokkaido & 3 & $3.1( \pm 1)$ & 2 & 3.8 & \\
\hline \multirow[t]{3}{*}{$\mathrm{MON}\left(10^{9} / 1\right)$} & Akita & 29 & $0.6( \pm 0.3)$ & 0.2 & 1.2 & $0.0-1.8$ \\
\hline & Shiba & 42 & $0.5( \pm 0.2)$ & 0.2 & 1.3 & \\
\hline & Hokkaido & 3 & $0.7( \pm 0.1)$ & 0.6 & 0.8 & \\
\hline \multirow[t]{3}{*}{ GRAN $\left(10^{9} / 1\right)$} & Akita & 29 & $8.3( \pm 4.3)$ & 3.4 & 19.8 & $4.0-12.6$ \\
\hline & Shiba & 42 & $8.4( \pm 2.2)$ & 3.9 & 15.6 & \\
\hline & Hokkaido & 3 & $8.0( \pm 3.6)$ & 3.9 & 10.5 & \\
\hline \multirow[t]{3}{*}{ \%LYMPH (\%) } & Akita & 29 & $28.6( \pm 10.8)$ & 8.8 & 52.9 & $12.0-30.0$ \\
\hline & Shiba & 42 & $21.8( \pm 7.5)$ & 3.4 & 41.8 & \\
\hline & Hokkaido & 3 & $27.5( \pm 3.2)$ & 25.6 & 31.2 & \\
\hline \multirow[t]{3}{*}{$\% \mathrm{MON}(\%)$} & Akita & 29 & $4.7( \pm 1.3)$ & 2 & 7.7 & $2.0-9.0$ \\
\hline & Shiba & 42 & $4.6( \pm 0.9)$ & 2.8 & 7.4 & \\
\hline & Hokkaido & 3 & $6.7( \pm 2.4)$ & 4.9 & 9.4 & \\
\hline \multirow[t]{3}{*}{$\%$ GRAN (\%) } & Akita & 29 & $66.7( \pm 11)$ & 43.1 & 89.2 & $60.0-83.0$ \\
\hline & Shiba & 42 & $72.9( \pm 7.3)$ & 54.1 & 85.9 & \\
\hline & Hokkaido & 3 & $65.8( \pm 5.6)$ & 59.4 & 69.5 & \\
\hline \multirow[t]{3}{*}{$\% \operatorname{EOS}(\%)$} & Akita & 29 & $2.9( \pm 2.9)$ & 0.5 & 13.7 & \\
\hline & Shiba & 42 & $3.6( \pm 7.9)$ & 0.6 & 50.8 & \\
\hline & Hokkaido & 3 & $1.4( \pm 0.1)$ & 0 & 2.2 & \\
\hline \multirow[t]{3}{*}{$\mathrm{RBC}\left(10^{12} / 1\right)$} & Akita & 29 & $7.4( \pm 0.1)$ & 5.2 & 8.9 & $5.50-8.50$ \\
\hline & Shiba & 42 & $7.9( \pm 1.2)$ & 4.5 & 10.3 & \\
\hline & Hokkaido & 3 & $7.8( \pm 3)$ & 4.5 & 10 & \\
\hline \multirow[t]{3}{*}{$\mathrm{HGB}(\mathrm{g} / \mathrm{l})$} & Akita & 29 & $138.9( \pm 20.2)$ & 97 & 174 & $110-190$ \\
\hline & Shiba & 42 & $156.8( \pm 20.1)$ & 119 & 187 & \\
\hline & Hokkaido & 3 & $147.0( \pm 54.3)$ & 85 & 186 & \\
\hline \multirow[t]{3}{*}{ НCT (\%) } & Akita & 29 & $46.8( \pm 6.3)$ & 34.3 & 59.5 & $39.0-56.0$ \\
\hline & Shiba & 42 & $52.7( \pm 6.1)$ & 41.4 & 64.9 & \\
\hline & Hokkaido & 3 & $48.3( \pm 17.6)$ & 28.4 & 61.6 & \\
\hline \multirow[t]{3}{*}{$\overline{\mathrm{MCV}(\mathrm{fl})}$} & Akita & 29 & $63.8( \pm 4.5)$ & 55.7 & 79.9 & $62.0-72.0$ \\
\hline & Shiba & 42 & $66.6( \pm 5.8)$ & 55.7 & 79.6 & \\
\hline & Hokkaido & 3 & $61.8( \pm 1.9)$ & 55.9 & 63.6 & \\
\hline \multirow[t]{3}{*}{$\mathrm{MCH}(\mathrm{pg})$} & Akita & 29 & $18.8( \pm 0.8)$ & 17.3 & 20.4 & $20.0-25.0$ \\
\hline & Shiba & 42 & $19.3( \pm 2)$ & 8.7 & 22.4 & \\
\hline & Hokkaido & 3 & $18.7( \pm 0.3)$ & 18.5 & 19 & \\
\hline \multirow[t]{3}{*}{$\overline{\mathrm{MCHC}(\mathrm{g} / \mathrm{l})}$} & Akita & 29 & $296.2( \pm 13.1)$ & 251 & 312 & $300-380$ \\
\hline & Shiba & 42 & $292.3( \pm 36.9)$ & 113 & 340 & \\
\hline & Hokkaido & 3 & $303.0( \pm 5.3)$ & 299 & 309 & \\
\hline
\end{tabular}


Table. 1 Haematologic indices of the Akita, Shiba, and Hokkaido breeds.

\begin{tabular}{|c|c|c|c|c|c|c|}
\hline Indicator & Breed & $\mathrm{N}$ & Mean $\pm \mathrm{SD}$ & Min & Max & Range \\
\hline \multirow[t]{3}{*}{ RDW (\%) } & Akita & 29 & $13.7( \pm 1.1)$ & 12 & 15.6 & $11.0-15.5$ \\
\hline & Shiba & 42 & $14.6( \pm 1.5)$ & 11.7 & 21.3 & \\
\hline & Hokkaido & 3 & $13.8( \pm 0.8)$ & 13.4 & 14.7 & \\
\hline \multirow[t]{3}{*}{$\operatorname{PLT}\left(10^{9} / 1\right)$} & Akita & 29 & $185.0( \pm 80.8)$ & 28 & 342 & $117-460$ \\
\hline & Shiba & 42 & $290.6( \pm 71)$ & 143 & 461 & \\
\hline & Hokkaido & 3 & $303.0( \pm 178.4)$ & 108 & 458 & \\
\hline \multirow[t]{3}{*}{ MPV (fl) } & Akita & 29 & $9.4( \pm 1.1)$ & 7.6 & 11.1 & $7.0-12.9$ \\
\hline & Shiba & 42 & $9.4( \pm 0.7)$ & 8.2 & 10.9 & \\
\hline & Hokkaido & 3 & $8.0( \pm 0.9)$ & 7.3 & 9 & \\
\hline \multirow[t]{3}{*}{ PDW (\%) } & Akita & 29 & $16.4( \pm 0.4)$ & 15.8 & 17.3 & \\
\hline & Shiba & 42 & $16.0( \pm 0.3)$ & 15.5 & 16.8 & \\
\hline & Hokkaido & 3 & $15.9( \pm 0.6)$ & 15.5 & 16.6 & \\
\hline \multirow[t]{3}{*}{ PCT (\%) } & Akita & 29 & $0.2( \pm 0.1)$ & 0.1 & 0.3 & \\
\hline & Shiba & 42 & $0.3( \pm 0.2)$ & 0.2 & 0.4 & \\
\hline & Hokkaido & 3 & $0.2( \pm 0.1)$ & 0.1 & 0.4 & \\
\hline
\end{tabular}

WBC - total white blood cell count; LYMPH - lymphocytes; MON - monocytes; GRAN granulocytes; $\%$ LYMPH - \% lymphocytes; \% MON - \% monocytes; \% GRAN - \% granulocytes; \% EOS - \% eosinophils; RBC - total red blood cell count; HGB - haemoglobin; HCT - haematocrit; MCV - mean red blood cell volume; $\mathrm{MCH}$ - mean cell haemoglobin; MCHC - mean cell haemoglobin concentration; RDW - red cell distribution width; PLT - total platelet count; MPV - mean platelet volume; PDW - platelet distribution width; PCT - platelet haematocrit; $\mathrm{SD}$ - standard deviation
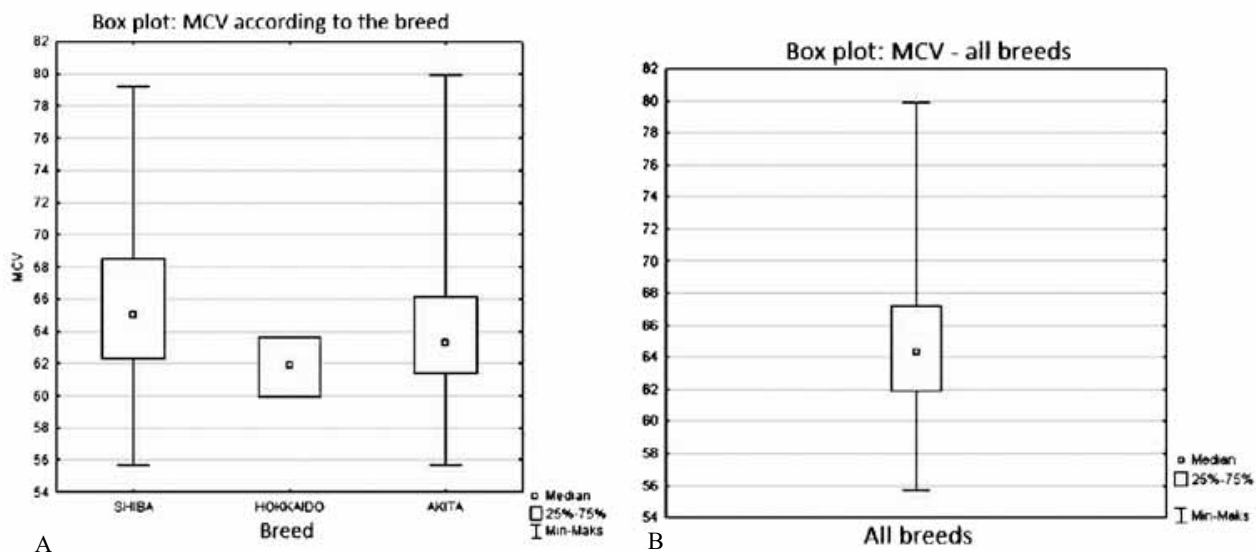

Fig. 1. The results of mean red blood cell volume (MCV) for (A) the Shiba, Akita, and Hokkaido breeds; and (B) all the breeds combined

than those in mixed breed dogs with high potassium concentration (HK), whereas MCV was higher when compared with dogs with low potassium concentration (LK) belonging to the same family (Maede et al. 1983). The HGB concentration, PCV, 


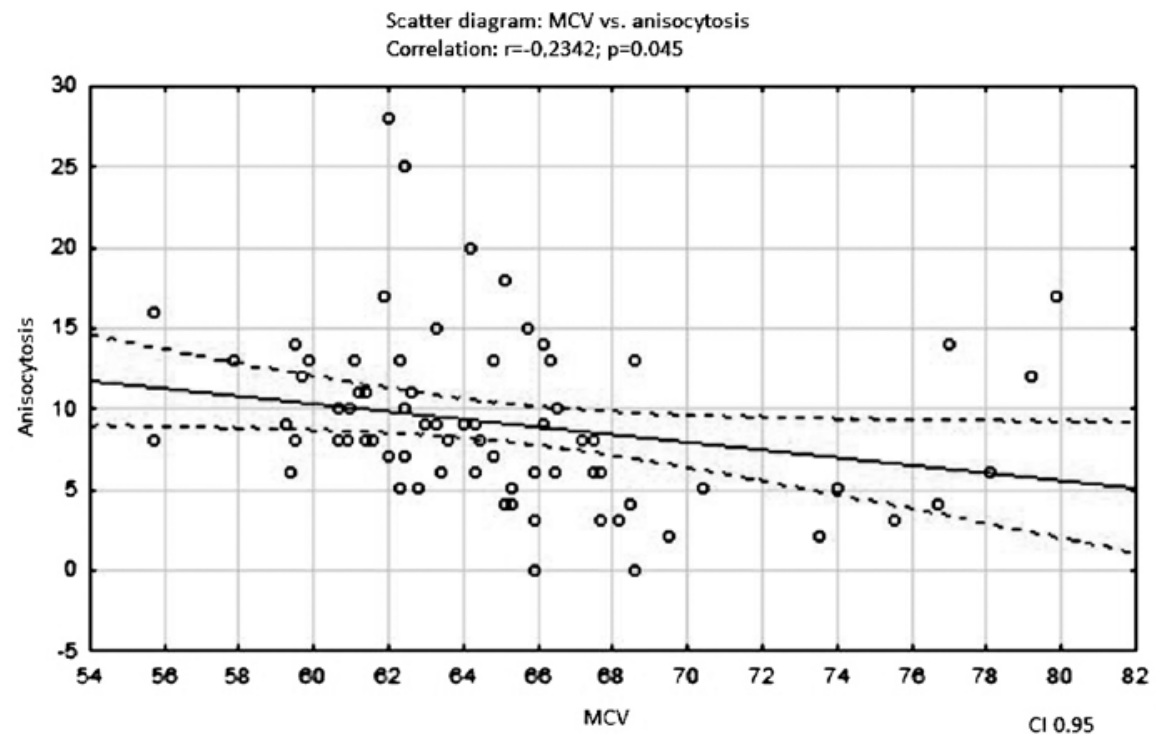

Fig. 2. Correlation between mean red blood cell volume (MCV) and anisocytosis. Correlation $r=-0.2342$; $P=0.045$

$\mathrm{RBC}$ and MCHC were significantly lower with HK in comparison with LK dogs and often were lower than the referential values (Conrado et al. 2014). Mean MCV in HK dogs was significantly higher than in LK dogs, nonetheless, the values were within the referential range (Kaneko et al. 2008). The HK phenotype dog studies revealed that HGB, PCV, RBC and MCHC values may be lower in those animals. This suggests that the increase in intracellular fluids may cause lower MCHC and higher MCV in those animal in regard to the normal range of the other variables (Maede et al. 1983; Battis on 2007). This may also lead to osmotic changes within red blood cells. In this study, the reduced values of $\mathrm{MCH}$ and MCHC indices were diagnosed in $75.7 \%$ and $40.5 \%$ dogs, respectively. Up to this point, HK phenotype was described in 10 out of 13 Japanese breeds and the frequency of its occurrence in the Akita breed is equal to $26.3 \%$ (Tanabe 2006) and 20\% according to Fujise et al. (1997) and Conrado et al. (2014). This study did not evaluate $\mathrm{K}$ and $\mathrm{Na}$ ion concentrations, though it is known that Akita HK phenotype is distributed worldwide. In comparison to mixed breed dogs, dogs of the Japanese breeds have reduced $\mathrm{MCH}, \mathrm{MCHC}$ and significant anisocytosis in the blood smear and a higher RDW indicator. Veterinarians should consider those differences when interpreting blood morphology test results.

\section{Conflict of interest}

The authors have no affiliations or financial involvement with any organization or entity with a financial interest in, or in financial competition with the subject matter or materials discussed in this article.

\section{References}

Aung N, Ling HZ, Cheng AS, Aggarwal S, Flint J, Mendonca M, Rashid M, Kang S, Weissert S, Coats CJ, Richards T, Thomas M, Woldman S, Okonko DO 2013: Expansion of the red cell distribution width and evolving iron deficiency as predictors of poor outcome in chronic heart failure. Int J Cardiol 168: 1997-2002 Battison A 2007: Apparent pseudohyperkalemia in a Chinese Shar Pei dog. Vet Clin Pathol 36: 89-93

Campora C, Freeman KP, Lewis FI, Gibson G, Sacchini F, Sanchez-Vazquez MJ, Rainer C, Kawanishi DT, 
Chandraratna PA, Bauersachs RM, Reid CL, Rahimtoola SH, Meiselman HJ 1987: Changes in blood rheology in patients with stable angina pectoris as a result of coronary artery disease. Circulation 76: 15-20

Campora C, Freeman KP, Lewis FI, Gibson G, Sacchini F, Sanchez-Vazquez MJ 2011: Determination of hematological reference intervals in healthy adults greyhounds. J Small Anim Pract 52: 301-309

Conrado FO, Oliveira ST, Lacerda LA, Silva MO, Hlavac N, Gonzalez FH 2014: Clinicopathologic and electrocardiogaphic features of Akita dogs with high and low eythrocyte potassium phenotypes. Vet Clin Pathol 43: $50-54$

Davis B, Toivio-Kinnucan M, Schuller S, Boudreaux MK 2008: Mutation in beta 1-tubulin correlates with macrothrombocytopenia in Cavalier King Charles Spaniels. J Vet Intern Med 22: 540-545

Felker GM, Allen LA, Pocock SJ, Shaw LK, McMurray JJ, Pfeffer MA, Swedberg K, Wang D, Yusuf S, Michelson EL, Granger CB 2007: Red cell distribution width as a novel prognostic marker in heart failure: data from the CHARM Program and the Duke Databank. J Am Coll Cardiol 50: 40-47

Fujise H, Higa K, Nakayama T, Wada K, Ochiai H, Tanabe Y 1997: Incidence of dogs possessing red blood cells with high K in Japan and East Asia. J Vet Med Sci 59: 495-497

Guglielmini C, Poser H, Dalla Pria A 2013: Red blood cell distribution width in dogs with chronic degenerative valvular disease. J Am Vet Med Assoc 243: 858-862

Guyton AC, Hall JE 2006: Textbook of Medical Physiology. $11^{\text {th }}$ ed. Philadelphia, PA: Elsevier Saunders, pp 419-438

Hampole CV, Mehrotra AK, Thenappan T 2009: Usefulness of red cell distribution width as a prognostic marker in pulmonary hypertension. Am J Cardiol 104: 868-872

Hellhammer K, Zeus T, Verde PE, Veulemanns V, Kahlstadt L, Wolff G, Erkens R, Westenfeld R, Navarese EP, Merx MW, Rassaf T, Kelm M 2016: Red cell distribution width in anemic patients undergoing transcatheter aortic valve implantation. World J Cardiol 8: 220-230

Hodges J, Christopher MM 2011: Diagnostic accuracy of using erythrocyte indices and polychromasia to identify regenerative anemia in dogs. J Am Vet Med Assoc 238: 1452-1458

Kaneko JJ, Harvey JW, Bruss ML 2008: Appendix IX: blood analyte reference values in small and some laboratory animals. In: Kaneko JJ, Harvey JW, Bruss ML, eds. Clinical Biochemistry of Domestic Animals. $6^{\text {th }}$ ed. San Diego, CA: Academic Press, pp 889-895

Lippi G, Plebani M 2014: Red blood cell distribution width (RDW) and human pathology. One size fits all. Clin Chem Lab Med 52: 1247-1249

Lippi G, Salvagno GL, Guidi GC 2014: Red blood cell distribution width is significantly associated with aging and gender. Clin Chem Lab Med 52: 197-199

Maede Y, Inaba M, Taniguchi N 1983: Increase of Na-K-ATPase activity, glutamate, and aspartate uptake in dog erythrocytes associated with hereditary high accumulation of GSH, glutamate, glutamine, and aspartate. Blood 61: 493-499

Mazzotta E, Guglielmini C, Menciotti G, Contiero B, Baron Toaldo M, Berlanda M, Poser H 2016: Red blood cell distribution width, hematology, and serum biochemistry in dogs with echocardiographically estimated precapillary and postcapillary pulmonary arterial hypertension. J Vet Intern Med 30: 1806-1815

Montagnana M, Cervellin G, Meschi T, Lippi G 2012: The role of red blood cell distribution width in cardiovascular and thrombotic disorders. Clin Chem Lab Med 50: 635-641

Neiger R, Hadley J, Pfeiffer DU 2002: Differentiation of dogs with regenerative and non-regenerative anaemia on the basis of their red cell distribution width and mean corpuscular volume. Vet Rec 150: 431-434

Patel KV, Mohanty JG, Kanapuru B, Hesdorffer C, Ershler WB, Rifkind JM 2013: Association of the red cell distribution width with red blood cell deformability. Adv Exp Med Biol 765: 211-216

Peruzzi D, Gavazza A, Mesiti G, Lubas G, Scarselli E, Conforti A, Bendtsen C, Ciliberto G, La Monica N, Aurisicchio L 2010: A vaccine targeting telomerase enhances survival of dogs affected by B-cell lymphoma. Mol Ther 18: $1559-1567$

Porter JA Jr, Canaday WR Jr 1971: Hematologic values in mongrel and greyhound dogs being screened for research use. J Am Vet Ned Assoc 159: 1603-1606

Rørtveit R, Sævik BK, Eggertsdottir AV 2015: Age-related changes in hematologic and serum biochemical variables in dogs aged 16-60 days. Vet Clin Pathol 44: 47-57

Schalm OW 1976: Erythrocyte macrocytosis in miniature and toy poodles. Canine Pract 3: 55-57

Singh MK, Lamb WA 2005: Idiopathic thrombocytopenia in Cavalier King Charls Spaniels. Aust Vet J 83: 700-703

Sullivan PS, Evans HL, McDonalds TP 1994: Platelet concentration and hemoglobin function in greyhounds. J Am Vet Med Assoc 205: 838-841

Swann JW, Sudunagunta S, Covey HL 2014: Evaluation of red cell distribution width in dogs with pulmonary hypertension. J Vet Cardiol 16: 227-235

Tanabe Y 2006: Phylogenetic studies of dogs with emphasis on Japanese and Asian breeds. Proc Japan Acad 82: 375-387

Torres AR, Cassle SE, Haymore M, Hill RC 2014: Hematologic differences between Dachshunds and mixed breed dogs. Vet Clin Path 43: 519-524

Zaldivar-Lopez S, Marin LM, Lazbik MC, Westendorf-Stingle N, Hensley S, Couto CG 2011: Clinical pathology of Greyhounds and other sighthounds. Vet Clin Pathol 40: 414-425 